\title{
Central line-associated blood stream infections in pediatric intensive care units: Longitudinal trends and compliance with bundle strategies.
}

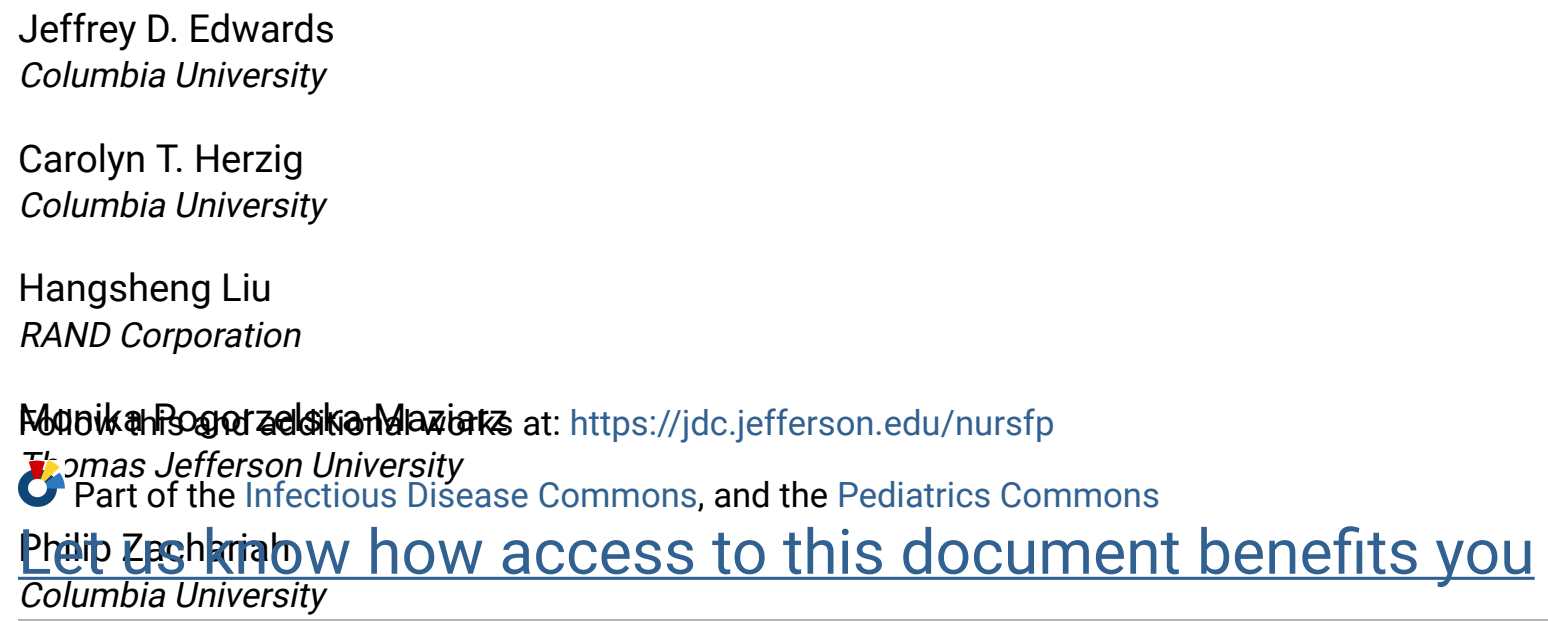

\section{Recommended Citation}

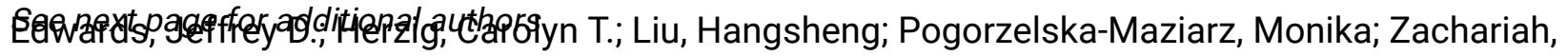
Philip; Dick, Andrew W.; Saiman, Lisa; Stone, Patricia W.; and Furuya, E. Yoko, "Central lineassociated blood stream infections in pediatric intensive care units: Longitudinal trends and compliance with bundle strategies." (2015). College of Nursing Faculty Papers \& Presentations. Paper 78.

https://jdc.jefferson.edu/nursfp/78

This Article is brought to you for free and open access by the Jefferson Digital Commons. The Jefferson Digital Commons is a service of Thomas Jefferson University's Center for Teaching and Learning (CTL). The Commons is a showcase for Jefferson books and journals, peer-reviewed scholarly publications, unique historical collections from the University archives, and teaching tools. The Jefferson Digital Commons allows researchers and interested readers anywhere in the world to learn about and keep up to date with Jefferson scholarship. This article has been accepted for inclusion in College of Nursing Faculty Papers \& Presentations by an authorized administrator of the Jefferson Digital Commons. For more information, please contact: JeffersonDigitalCommons@jefferson.edu. 


\section{Authors}

Jeffrey D. Edwards, Carolyn T. Herzig, Hangsheng Liu, Monika Pogorzelska-Maziarz, Philip Zachariah, Andrew W. Dick, Lisa Saiman, Patricia W. Stone, and E. Yoko Furuya 


\title{
Central line-associated blood stream infections in pediatric ICUs: Longitudinal trends and compliance with bundle strategies
}

\author{
Jeffrey D Edwards, MD, MA, MAS ${ }^{1}$, Carolyn TA Herzig, MS $^{2}$, Hangsheng Liu, PhD $^{3}$, Monika \\ Pogorzelska-Maziarz, PhD, MPH ${ }^{4}$, Philip Zachariah, MD $^{5}$, Andrew W Dick, PhD $^{3}$, Lisa \\ Saiman, MD, MPH ${ }^{5,6}$, Patricia W Stone, PhD, RN ${ }^{2}$, and E Yoko Furuya, MD, $\mathbf{M S}^{6,7}$ \\ ${ }^{1}$ Division of Pediatric Critical Care Medicine, Columbia University College of Physicians and \\ Surgeons, New York, NY \\ ${ }^{2}$ Center for Health Policy, Columbia University School of Nursing, New York, NY \\ ${ }^{3}$ RAND Corporation, Boston, MA \\ 4 Jefferson School of Nursing, Thomas Jefferson University, Philadelphia, PA \\ ${ }^{5}$ Division of Pediatric Infectious Diseases, Columbia University College of Physicians and \\ Surgeons, New York, NY \\ ${ }^{6}$ Department of Infection Prevention and Control, NewYork-Presbyterian Hospital, New York, NY \\ 7 Division of Infectious Diseases, Columbia University College of Physicians and Surgeons, New \\ York, NY
}

\section{Abstract}

Background-Knowing the temporal trend central line-associated bloodstream infection (CLABSI) rates among U.S. pediatric intensive care units (PICU), the current extent of CL bundle compliance, and the impact of compliance on rates is necessary to understand what has been accomplished and can be improved in CLABSI prevention.

\begin{abstract}
Methods-Longitudinal study of PICUs in National Healthcare Safety Network hospitals and a cross-sectional survey of directors/managers of infection prevention \& control departments regarding PICU CLABSI prevention practices, including self-reported compliance with elements of central line bundles. Associations between 2011/12 PICU CLABSI rates and infection prevention practices were examined.
\end{abstract}

\footnotetext{
(C) 2015 by the Association for Professionals in Infection Control and Epidemiology, Inc. Elsevier Inc. All rights reserved Corresponding author: Jeffrey Edwards, Division of Pediatric Critical Care Medicine, Columbia University College of Physicians and Surgeons, 3959 Broadway, CHN 10-24, New York, NY 10032, Phone: (212) 305-8458, jde2134@ columbia.edu.

Publisher's Disclaimer: This is a PDF file of an unedited manuscript that has been accepted for publication. As a service to our customers we are providing this early version of the manuscript. The manuscript will undergo copyediting, typesetting, and review of the resulting proof before it is published in its final citable form. Please note that during the production process errors may be discovered which could affect the content, and all legal disclaimers that apply to the journal pertain.

This study was performed at Columbia University Medical Center.

Conflict of Interest Disclosures: The authors have no potential conflicts of interest to disclose.
} 
Results-Reported CLABSI rates decreased during the study period, from 5.8 per 1000 line days in 2006 to 1.4 in 2011/12 ( $\mathrm{P}<0.001)$. While $73 \%$ of PICUs had policies for all central line prevention practices, only $35 \%$ of those with policies reported $\$ 95 \%$ compliance. PICUs with $\geq 95 \%$ compliance with central line infection prevention policies had lower reported CLABSI rates, but this association was statistically insignificant.

Conclusions-There was a non-significant trend in decreasing CLABSI rates as PICUs improved bundle policy compliance. Given that few PICUs reported full compliance with these policies, PICUs increasing their efforts to comply with these policies may help reduce CLABSI rates.

\section{Keywords}

Intensive Care Units; Pediatric; Catheter-Related Infections; Policy

\section{Introduction}

Central line-associated bloodstream infections (CLABSI) are a major source of hospitalacquired infections (HAI) in intensive care unit (ICU) patients, including pediatric ICU (PICU) patients, and are associated with increased morbidity, mortality, and costs. ${ }^{12}$ Encouraged by organizations such as the Institute for Healthcare Improvement ${ }^{3}$ and publications such as the Keystone study ${ }^{4}$ in 2006 , ICUs have increasingly sought to prevent CLABSIs through the use of sets of evidence-based practices, or "care bundles."

Since the adoption of central line (CL) bundle policies and other practices, CLABSI rates among ICUs collectively have fallen nearly $60 \%$ in the previous decade. ${ }^{56}$ This aggregate data is heavily skewed towards adult ICUs given their greater number compared to PICUs. ${ }^{7}$ There has only been one multi-institutional study of the overall trend of CLABSI rates in PICUs in the era of CL bundle practices. ${ }^{8}$

Single center studies and multicenter collaborative quality improvement efforts performed in PICUs in the U.S. have demonstrated that implementation of bundle strategies were associated with a reduction in CLABSI rates. ${ }^{9}$ Others have suggested that in the PICU population, maintenance strategies may have a more significant impact on CLABSI rates than insertion strategies ${ }^{101112}$, while others have shown that specific maintenance strategies, e.g., chlorhexidine entry scrubs or sponges, were not associated with reduced CLABSI rates. ${ }^{13}$ However, little is known about specific prevention practices or about the impact of these and other practices in a larger nation-wide sample.

Knowing the trend of PICU CLABSI rates, the current extent of CL bundle compliance, and the impact of compliance on rates among a large cohort of U.S. PICUs is necessary to understand what has been accomplished and can be improved in CLABSI prevention. Therefore, we conducted a multi-institutional longitudinal study of National Healthcare Safety Network (NHSN) hospitals with PICUs to describe their PICU-specific CLABSI rates over time and a cross-sectional study of their adoption of and compliance with specific CLABSI prevention practices. We also investigated the association between these rates and hospital/PICU characteristics, institutional HAI prevention practices, and PICU-specific 
compliance with bundle elements. We hypothesized that higher compliance with CL bundle practices would be associated with lower PICU CLABSI rates.

\section{Methods}

\section{Study Design and Study Hospitals}

In 2011, infection prevention \& control (IP\&C) departments of non-veteran NHSN hospitals were invited to participate in a study (Prevention of Nosocomial infections and Cost Effectiveness Refined [P-NICER]) to assess the impact of infection prevention processes and state mandated HAI reporting on ICU HAI rates. The NHSN is the Centers for Disease Control and Prevention's (CDC) national HAI surveillance system. ${ }^{14}$ Participation in the PNICER NHSN group entailed completion of an online survey (see below) and permission for the P-NICER study team to access the hospital's NHSN data. ${ }^{15}$ Among other data, this included the number of ICU-specific device-associated infections and number of device days from time of entry into NHSN (as early as 2006) through mid-2012, as well as institutional characteristics. Data were reported by hospitals using standard NHSN definitions and methodologies ${ }^{16}$, which are recognized as the gold standard for HAI surveillance. ${ }^{1718}$ Additional detail on this survey and its methodology has been published elsewhere. ${ }^{1920}$

This current analysis focuses on PICUs and their hospitals among the larger group of NHSN hospitals. At the end of 2011, there were 3,374 non-veteran NHSN hospitals, of which 342 $(10 \%)$ had a PICU. Characteristics of the participating hospitals and their PICUs were collected through NHSN, including their geographical region (Northeast, South, Midwest, or West), institution type (general vs. free-standing children's hospital), medical school affiliation (yes vs. no), unit type (medical/surgical or medical vs. cardiothoracic), and number of ICU beds ( $\leq 5$ vs. >15). Medical/surgical and medical units were grouped together because there were only 8 medical units. We also evaluated the proportion of hospitals that were located in states that had mandatory reporting of CLABSI rates before December 2011. To determine whether PICU CLABSI data submission was mandatory, pertinent HAI laws (state statutes, administrative regulations, and other administrative requirements) were systematically reviewed for all U.S. states and territories. ${ }^{21}$

\section{Survey of Infection Prevention Practices}

A psychometrically-tested online survey assessing infection prevention \& control (IP\&C) policies and practices was adapted from previous research. ${ }^{1920}$ Survey respondents were the director or manager of the hospital's IP\&C department. The survey inquired if the institution had an electronic surveillance system for tracking HAI, a policy of antibiotic stewardship/ restriction, and specific policies and practices related to CL infection control. In addition to investigating policies and practices related to CL insertion in adult ICUs, the survey also asked about PICU-specific policies and practices if the hospital had a PICU. Respondents were asked whether the PICU had written policies for checklist use at CL insertion, along with five CL bundle elements (choice of optimal catheter insertion site, chlorhexidine skin disinfection, maximal barrier precautions, and monitoring of hand hygiene practices, and assessment of daily line necessity). Respondents were also asked to report percent 
compliance with each written policy during the last period monitored. Compliance was categorized as all of the time (95-100\% [ie, full compliance]), usually (75-94\%), sometimes $(25-74 \%)$, rarely/never ( $<25 \%)$, don't know, or no monitoring was performed. We report the aggregate presence of and compliance with these CL policies in the study PICUs.

\section{CLABSI Rates and Statistical Analyses}

Mean PICU CLABSI rates per 1000 CL days were calculated by dividing the summed number of CLABSI events by the summed number of CL device days, multiplied by 1000 . As recommended by the CDC, mean overall rates were weighted by the summed number of CL days in order to calculate "pooled" means. As opposed to averaging mean rates across units, pooled means permit more efficient, less biased estimates because they do not ignore unit-level variation of device utilization and avoid potentially overestimating rates by including the number of CL days of those PICUs that had zero infections in the numerator. Pooled mean CLABSI rates are presented with their standard deviations (SD) and 95\% confidence intervals (CI).

To illustrate the trend of CLABSI rates between 2006 and mid-2012, we report pooled mean rates by year; 2011 and 2012 data were combined because only 4-6 months of 2012 data were available depending on the unit and because the same hospitals/units participated in both of these periods. A Wald test of composite linear hypotheses was performed to determine if the mean CLABSI rates were equivalent between the different years.

To determine the association between CLABSI rates in 2011 and mid-2012 and institutional characteristics, institutional HAI prevention practices, and PICU-specific compliance with bundle elements as reported in the survey, we used unadjusted negative binomial regression modeling. ${ }^{22}$ The sum of CL days was used as the exposure variable. Negative binomial modeling was used because it adjusts variance independently from the mean and is more flexible in regards to overdispersion, as opposed to Poisson modeling. Levels of compliance to the bundle policies and other responses to the survey's compliance questions ("do not know", "no monitoring", and no response) were treated as a categorical independent variable in these unadjusted regression models, with $\geq 95 \%$ compliance being the reference. To investigate the association between CLABSI rates and high compliance with multiple bundle policies, we fitted an unadjusted negative binomial regression model with number of bundle policies for which there was $\$ 95 \%$ reported compliance as the categorical independent variable. In this case, $\geq 95 \%$ compliance with all six policies was the reference. In a sensitivity analysis, we examined the association between CLABSI rates in 2011 and mid-2012 and PICU-specific compliance with bundle elements, excluding units whose reported compliance rates were missing or the respondent indicated "don't know."

Statistical significance was determined using a $p$ value $<0.05$. Stata 12 (StataCorp, College Station, TX) was used for statistical analyses. All procedures were reviewed and approved by institutional review boards at Columbia University Medical Center and RAND Corporation. 


\section{Results}

In 2011, 88 NHSN hospitals with 99 PICUs from 34 states participated and comprise our study cohort. This cohort represented $26 \%$ of eligible NHSN hospitals with PICUs who reported CLABSI rates to NHSN in that year. The characteristics of our cohort hospitals and PICUs are presented in Table 1. The majority of these hospitals were general (i.e., not freestanding children's) hospitals (82\%), affiliated with medical schools (88\%), and in states with mandatory reporting of PICU CLABSIs (59\%). The majority of PICUs were medical or medical/surgical $(91 \%)$ and had 15 or fewer beds $(70 \%)$.

The mean CLABSI rates by year and the number of hospitals/PICUs that contributed data each year are presented in Table 2. The CLABSI rates decreased each year from 2006, and a Wald test of linear hypotheses showed that these mean yearly rates were statistically different ( $<$ 0.001). Using 2011 to mid-2012 CL data, the pooled mean CLABSI rate for all PICUs was 1.42 per 1000 CL days.

The 2011 survey of infection prevention practices revealed that 68 (77\%) hospitals had a policy for antibiotic stewardship, but only 41 (47\%) had an electronic surveillance system for tracking HAI. Table 3 shows the CLABSI rates and unadjusted comparisons across institutional characteristics and IP\&C practices in 2011/12. There were no statistical differences in CLABSI rates by institutional characteristics or whether hospitals were located in a state with mandatory PICU CLABSI reporting. Similarly, there were no statistical differences in CLABSI rates when hospitals had an electronic surveillance system for tracking HAI or a policy of antibiotic stewardship/restriction.

The proportion of PICUs with written policies for the CL insertion checklist or one of the five specific bundle elements ranged from $86 \%$ (checking for daily line necessity) to $95 \%$ (use of barrier precautions during insertion). Among PICUs with policies, $295 \%$ compliance was found to be the highest with hand hygiene practices (58\%) and lowest with checking for daily line necessity (40\%). Seventy-two (73\%) PICUs had a policy for the insertion checklist and all five bundle practices, and 35\% (25 of 72) of these PICUs had $295 \%$ compliance with all six infection prevention policies. The proportions of PICUs with specific CL policies and their reported compliance with those policies are presented in Table 4.

Table 4 also shows the CLABSI rates and unadjusted comparisons across levels of selfreported compliance with central line bundle policies and other survey responses in 2011/ mid-2012. While CLABSI rates were generally lower when PICUs had $\$ 95 \%$ compliance with specific bundle policies compared to $<95 \%$ compliance or other survey responses, these lower rates were not statistically different. The two exceptions were identifying optimal catheter site and monitoring hand hygiene practices; in both these cases, $\geq 95 \%$ compliance was associated with statistically lower CLABSI rates compared to 75-94\% compliance. In our sensitivity analysis excluding units with missing reported compliance rates or with the respondent indicating "don't know", there was no substantial difference in our results. 


\section{Discussion}

This study is the largest survey to assess CL bundle policies and practices in PICUs reported to date. Using multi-institutional, longitudinal data, this study demonstrates the trend of PICU CLABSI rates and reports the IP\&C/CL bundle policies and practices of these PICUs and how they related to infection rates. We observed that CLABSI rates have fallen significantly since 2006, but this decline may have plateaued since 2010. We also found that while a sizable majority of PICUs had a policy for one or more specific CL bundle practices, a substantially lower proportion of PICUs reported full compliance with their policies. Among those PICUs with those policies, only about one third of them were fully compliant. There is a suggestion that full compliance with CL prevention practices is associated with lower CLABSI rates as compared to less than full compliance, but this was only shown for certain bundle elements (optimal catheter site and monitoring hand hygiene practices) and not others. While a relatively large number of PICUs were included in the study, the lack of statistical differences comparing the majority of levels of bundle element compliance may have been due to a still insufficient sample size.

In regards to the overall lack of association found between bundle practices and CLABSI rates, our study evaluated more bundle elements related to CL insertion than maintenance. Data from the NACHRI collaborative suggests that CLABSI prevention strategies around CL maintenance may be relatively more important in PICUs, compared to insertion strategies. ${ }^{12-14}$ By contrast, in the larger P-NICER study of adult ICUs, lower CLABSI rates were associated with $\geq 95 \%$ monitored compliance with CL bundle policies. Similarly, in our sub-study of P-NICER sites with a neonatal ICU, $295 \%$ compliance with the use of a checklist for insertion and assessment of daily line necessity were significantly associated with lower CLABSI rates. ${ }^{23}$

Before concluding that compliance with several maintenance CL bundles in PICUs is not important for lowering CLABSI rates, it is necessary to consider how relatively few PICUs were fully compliant with all or even individual CL bundle policies. While PICU CLABSI rates have fallen significantly over recent years, it appears that PICUs still have much opportunity to improve their implementation of and adherence with certain CL bundles practices. Perhaps PICUs could reduce CLABSI rates even further if CL bundle compliance improved. $^{24}$

Strengths of this study include the fact that it surveyed CL bundle practices in 99 PICUs in the real-world setting, as opposed to studies focusing just on PICUs with CL qualityimprovement collaboratives. Thus, this study presumably captured data from PICUs that were actively enacting or fostering adherence to bundle policies and those that were not, potentially making the reported compliance and CLABSI rates less biased and more generalizable. Moreover, our cohort was composed of PICUs both in free-standing children's hospitals and within general hospitals.

Our study has a number of limitations. First, our cohort of hospitals represented only $26 \%$ of eligible NHSN hospitals with PICUs, which may have introduced selection bias into our sample and limited generalizability. However, according to analysis provided by the CDC to 
the PNICER group, the mean CLABSI rate of the study's PICUs was not statistically different from the mean CLABSI rate of PICUs in non-participating hospitals. ${ }^{17}$ Second, as a cross-sectional survey, we requested self-reported compliance in only one recently monitored period, and there was no external audit of their compliance. We also assumed that this reported compliance reflected actual compliance for the entire 2011/mid-2012 period in our tests of association between compliance and CLABSI rates, which may not have been an accurate assumption. Third, we did not control for severity of illness, underlying chronic conditions, or other patient-level factors in our analyses of CLABSI rates. ${ }^{1225}$ Similarly, we did not report or control for PICUs that were actively participating in quality-improvement collaboratives or initiatives to lower CLABSI rates. Fourth, we focused primarily on the most widely disseminated CL insertion elements and only investigated one CL maintenance element, although there may be growing evidence that compliance with maintenance practices may be as or more important than compliance with insertion practices in efforts to decrease infection rates. ${ }^{12-14}$ Therefore, we cannot comment on several potentially important infection control practices, such as ethanol/antibiotic locks, minimizing entering the CL, and peripheral versus centrally-obtained blood cultures. Fifth, the decline in the CLABSI rate during the study period may have been partly due to a change in the CDC's CLABSI definition. ${ }^{26}$ Finally, although this is a large survey of PICU CL bundle policies and practices and their relation to CLABSI rates, the sample size might still be too small to detect a meaningful difference in some practices.

\section{Conclusion}

Recent years have seen a dramatic decrease in CLABSI rates in inpatient settings, including PICUs. This decrease is likely due in part to the implementation of CL bundles, as demonstrated by prior studies. Nevertheless, the CDC and other organizations continue to advocate for zero CLABSIs, as this HAI is thought to be completely preventable. Among this large cohort of PICUs, most had CL bundle policies, and CLABSI rates were low. However, strict compliance with these bundle polices was unsatisfactorily rare, and CLABSIs continue to occur. Future efforts to further prevent CLABSIs should focus on increasing compliance with these and other bundle practices and studying the resulting impact on infection rates.

\section{Acknowledgements}

We would like to thank all of the survey respondents and hospitals who participated and provided data for the study. We also would like to acknowledge other research team members, including T. Horan and E. Larson, and L. Wiener from the CDC. All phases of this study were supported by an NIH grant-National Institute of Nursing Research R01NR010107 (Stone, PI).

\section{References}

1. Klevens RM, Edwards JR, Richards CL Jr, Horan TC, Gaynes RP, Pollock DA, et al. Estimating health care-associated infections and deaths in U.S. hospitals, 2002. Public Health Rep. 2007; 122:160-166. [PubMed: 17357358]

2. Nowak JE, Brilli RJ, Lake MR, Sparling KW, Butcher J, Schulte M, et al. Reducing catheterassociated bloodstream infections in the pediatric intensive care unit: Business case for quality improvement. Pediatr Crit Care Med. 2010; 11:579-587. [PubMed: 20308931] 
3. Berwick DM, Calkins DR, McCannon CJ, Hackbarth AD. The 100,000 lives campaign: setting a goal and a deadline for improving health care quality. JAMA. 2006; 295:324-327. [PubMed: 16418469]

4. Pronovost P, Needham D, Berenholtz S, Sinopoli D, Chu H, Cosgrove S, Sexton B, et al. An intervention to decrease catheter-related bloodstream infections in the ICU. N Engl J Med. 2006; 355:2725-2732. [PubMed: 17192537]

5. Centers for Disease Control and Prevention. Vital signs: central line-associated blood stream infections-United States, 2001, 2008, and 2009. MMWR Morb Mortal Wkly Rep. 2011; 60:243248. [PubMed: 21368740]

6. Gandra S, Ellison RT 3rd. Modern Trends in Infection Control Practices in Intensive Care Units. J Intensive Care Med. 2013 DOI: 10.1177/0885066613485215.

7. Wang HE, Yealy DM. Distribution of specialized care centers in the United States. Ann Emerg Med. 2012; 60:632-637.e7. [PubMed: 22633341]

8. Patrick SW, Kawai AT, Kleinman K, Jin R, Vaz L, Gay C, et al. Health Care-Associated Infections Among Critically Ill Children in the US, 2007-2012. Pediatrics. 2014; 134:1-8. [PubMed: 24918219]

9. Smulders CA, van Gestel JP, Bos AP. Are central line bundles and ventilator bundles effective in critically ill neonates and children? Intensive Care Med. 2013; 39:1352-1358. [PubMed: 23615702]

10. Niedner MF, Huskins WC, Colantuoni E, Muschelli J, Harris JM 2nd, Rice TB, et al. Epidemiology of central line-associated bloodstream infections in the pediatric intensive care unit. Infect Control Hosp Epidemiol. 2011; 32:1200-1208. [PubMed: 22080659]

11. Miller MR, Griswold M, Harris JM 2nd, Yenokyan G, Huskins WC, Moss M, et al. Decreasing PICU catheter-associated bloodstream infections: NACHRI's quality transformation efforts. Pediatrics. 2010; 125:206-213. [PubMed: 20064860]

12. Wheeler DS, Giaccone MJ, Hutchinson N, Haygood M, Bondurant P, Demmel K, et al. 2011; 128:e995-e1004.

13. Miller MR, Niedner MF, Huskins WC, Colantuoni E, Yenokyan G, Moss M, et al. Reducing PICU central line-associated bloodstream infections: 3-year results. Pediatrics. 2011; 128:e1077-1083. [PubMed: 22025594]

14. Centers for Disease Control and Prevention: National Healthcare Safety Network (NHSN). Available at: http://www.cdc.gov/nhsn/about.html. Accessed November 10, 2013

15. Stone PW, Pogorzelska-Maziarz M, Herzig CT, Weiner LM, Furuya EY, Dick A, et al. State of Infection Prevention in U.S. Hospitals Enrolled in NHSN. Am J Infect Control. 2014; 42:94-99. [PubMed: 24485365]

16. Centers for Disease Control and Prevention: NHSN manual: patient safety component protocol. 2008. Available: http://www.cdc.gov/ncidod/dhqp/pdf/nhsn/NHSN_Manual_ \%20Patient_Safety_Protocol022307.pdf. Accessed November 5, 2013

17. Horan TC, Emori TG. Definitions of key terms used in the NNIS System. Am J Infect Control. 1997; 25:112-116. [PubMed: 9113287]

18. Emori TG, Edwards JR, Culver DH, Sartor C, Stroud LA, Gaunt EE, et al. Accuracy of reporting nosocomial infections in intensive-care-unit patients to the National Nosocomial Infections Surveillance System: a pilot study. Infect Control Hosp Epidemiol. 1998; 19:308-316. [PubMed: 9613690]

19. Stone PW, Dick A, Pogorzelska M, Horan TC, Furuya EY, Larson E. Staffing and structure of infection prevention and control programs. Am J Infect Control. 2009; 37:351-357. [PubMed: 19201510]

20. Furuya EY, Dick A, Perencevich EN, Pogorzelska M, Goldmann D, Stone PW. Central line bundle implementation in US intensive care units and impact on bloodstream infections. PLoS One. 2011; 6:e15452. [PubMed: 21267440]

21. Herzig CT, Reagan J, Pogorzelska-Maziarz M, Srinath D, Stone PW. State mandated reporting of healthcare-associated infections in the US: Trends over time. Public Health Rep. 2014 DOI: 10.1177/1062860614540200.

22. Cameron, AC.; Trivedi, PK. Regression analysis of count data. Cambridge University Press; Cambridge [England]: 1998. 
23. Zachariah P, Furuya EY, Edwards JD, Dick A, Hangsheng L, Herzig C, et al. Compliance with prevention practices and their association with central line-associated blood stream infection rates in neonatal intensive care units. Am J of Infect Control. 2014; 35:1133-1139.

24. O'Grady NP, Alexander M, Burns LA, Dellinger EP, Garland J, Heard SO, et al. Summary of recommendations: Guidelines for the Prevention of Intravascular Catheter-related Infections. Clin Infect Dis. 2011; 52:1087-1099. [PubMed: 21467014]

25. Yogaraj JS, Elward AM, Fraser VJ. Rate, risk factors, and outcomes of nosocomial primary bloodstream infection in pediatric intensive care unit patients. Pediatrics. 2002; 110:481-485. [PubMed: 12205248]

26. Centers for Disease Control and Prevention. NHSN newsletter: revised LCBI definition. US Department of Health and Human Services, CDC; Atlanta, GA: 2007. Available at http:// www.cdc.gov/nhsn/pdfs/newsletters/january2008.pdf. Accessed February 10, 2014 


\section{Highlights}

- A longitudinal study of PICU CLABSI rates and survey of their prevention practices

- CLABSI rates fell significantly from 5.8 per 1000 line days in 2006 to 1.4 in 2011/12

- Compliance with optimal site and hand hygiene were associated with lower CLABSI rates

- Compliance with other policies or practices were not associated with less CLABSIs

- Only $25 \%$ of PICUs had $\geq 95 \%$ compliance with all studied prevention policies 


\section{Table 1}

Description of hospitals and pediatric ICUs

\begin{tabular}{lc}
\hline Characteristics & $\mathbf{N}(\boldsymbol{\%})$ \\
\hline Hospitals (n=88) & \\
Region & $22(25)$ \\
$\quad$ Northeast & $23(26)$ \\
$\quad$ South & $27(31)$ \\
$\quad$ Midwest & $16(18)$ \\
$\quad$ West & $52(59)$ \\
In state where CLABSI mandatory & \\
$\quad$ reporting in place before 2011 survey & \\
Institution type & $72(82)$ \\
$\quad$ General hospital & $16(18)$ \\
$\quad$ Free-standing children's hospital & $77(88)$ \\
Medical school affiliation & \\
$\quad$ PICUs (n=99) & \\
ICU type & \\
$\quad$ Medical/surgical or medical & $90(91)$ \\
$\quad$ Cardiothoracic & $9(9)$ \\
Number of beds & \\
$\quad>15$ & \\
\hline
\end{tabular}

CLABSI, central line-associated blood stream infection; PICU, pediatric intensive care unit 


\section{Table 2}

\begin{tabular}{|c|c|c|c|}
\hline & & & \\
\hline Year & Mean (SD) & $95 \%$ CI & $\begin{array}{c}\text { Number of } \\
\text { hospitals/PICUs } \\
\text { contributing data }\end{array}$ \\
\hline 2006 & $5.8(2.94)$ & $4.5-7.11$ & $21 / 22$ \\
\hline 2007 & $3.8(3.13)$ & $2.73-4.88$ & $33 / 36$ \\
\hline 2008 & $3.27(2.23)$ & $2.7-3.84$ & $53 / 62$ \\
\hline 2009 & $2.45(1.36)$ & $2.11-2.79$ & $57 / 67$ \\
\hline 2010 & 1.54 (1.19) & $1.28-1.8$ & $73 / 85$ \\
\hline $2011 / 2012$ & $1.42(1.07)$ & $1.21-1.64$ & $88 / 99$ \\
\hline
\end{tabular}

CI, confidence interval; CLABSI, central line-associated bloodstream infection; PICU, pediatric intensive care unit; SD, standard deviation 
Table 3

CLABSI rates and unadjusted comparisons across institutional characteristics and infection prevention \& control practices in 2011/mid-2012

\begin{tabular}{|c|c|c|c|}
\hline ICU type & Mean (SD) & $95 \% \mathrm{CI}$ & P value ${ }^{*}$ \\
\hline State mandatory reporting & & & 0.93 \\
\hline Yes & $1.38(0.96)$ & $1.14-1.63$ & \\
\hline No & $1.58(1.44)$ & $1.09-2.07$ & \\
\hline Region & & & 0.82 \\
\hline Northeast & $1.60(1.08)$ & $1.16-2.03$ & \\
\hline South & $1.03(1.15)$ & $0.55-1.52$ & \\
\hline Midwest & $1.60(1.09)$ & $1.18-2.03$ & \\
\hline West & $1.39(0.91)$ & $0.97-1.80$ & \\
\hline ICU type & & & 0.68 \\
\hline Medical/surgical or medical & $1.4(1.16)$ & $1.16-1.64$ & \\
\hline Cardiothoracic & $1.52(0.6)$ & $1.05-1.98$ & \\
\hline ICU size & & & 0.65 \\
\hline$\unlhd 5$ beds & $1.56(1.45)$ & $1.21-1.91$ & \\
\hline$>15$ beds & $1.36(0.85)$ & $1.05-1.68$ & \\
\hline Institution type & & & 0.26 \\
\hline General hospital & $1.58(1.3)$ & $1.28-1.88$ & \\
\hline Free-standing children's hospital & $1.29(0.82)$ & $0.95-1.63$ & \\
\hline Medical school affiliation & & & 0.36 \\
\hline Affiliated & $1.44(1.09)$ & $1.21-1.67$ & \\
\hline Not affiliated & $1.22(0.79)$ & $0.69-1.76$ & \\
\hline Electronic surveillance of HAI & & & 0.33 \\
\hline Yes & $1.36(0.98)$ & $1.08-1.64$ & \\
\hline No & $1.57(1.25)$ & $1.21-1.93$ & \\
\hline Antibiotic stewardship/restriction & & & 0.69 \\
\hline Yes & $1.49(1.16)$ & $1.22-1.76$ & \\
\hline No & $1.36(0.71)$ & $1.03--1.7$ & \\
\hline
\end{tabular}

CLABSI, central line-associated bloodstream infection; HAI, hospital associated infection; ICU, intensive care unit; SD, standard deviation

* Negative binomial regression using the sum of line device days as exposure variable 


\section{Table 4}

CLABSI rates and unadjusted comparisons across levels of self-reported compliance with specific central line infection prevention policies in 2011/mid-2012

\begin{tabular}{|c|c|c|c|c|}
\hline ICU type & $\begin{array}{l}\text { No. of } \\
\text { ICUs } \\
99(100 \%)\end{array}$ & Mean (SD) & $95 \% \mathrm{CI}$ & P value* \\
\hline \multicolumn{5}{|c|}{ Central line bundle insertion checklist } \\
\hline$\geq 95 \%$ compliance & $48(48)$ & $1.24(0.96)$ & $0.96-1.52$ & Ref \\
\hline $75-94 \%$ compliance & $12(12)$ & $1.88(1.51)$ & $0.92-2.84$ & 0.07 \\
\hline $25-74 \%$ compliance & $2(2)$ & $1.96(0.86)$ & $0-9.65$ & 0.51 \\
\hline Do not know & $12(12)$ & $1.40(1.08)$ & $0.71-2.08$ & 0.91 \\
\hline No monitoring & $12(12)$ & $1.58(0.66)$ & $1.16-2$ & 0.29 \\
\hline No response to question & $13(13)$ & $1.82(1.61)$ & $0.85-2.79$ & 0.32 \\
\hline \multicolumn{5}{|l|}{ Optimal catheter site } \\
\hline 295\% compliance & $45(45)$ & $1.21(0.96)$ & $0.93-1.5$ & Ref \\
\hline $75-94 \%$ compliance & $15(15)$ & $2.14(1.44)$ & $1.34-2.93$ & 0.03 \\
\hline $25-74 \%$ compliance & $1(1)$ & $1.54(-)$ & - & 0.79 \\
\hline Do not know & $12(12)$ & $1.36(1.24)$ & $0.57-2.16$ & 0.93 \\
\hline No monitoring & $12(12)$ & $1.31(0.8)$ & $0.81-1.82$ & 0.89 \\
\hline No response to question & $14(14)$ & $1.78(0.98)$ & $1.21-2.34$ & 0.11 \\
\hline \multicolumn{5}{|l|}{ Chlorhexidine skin disinfection } \\
\hline $295 \%$ compliance & $51(52)$ & $1.32(1.07)$ & $1.02-1.62$ & Ref \\
\hline $75-94 \%$ compliance & $13(13)$ & $1.56(1.06)$ & $0.91-2.2$ & 0.48 \\
\hline $25-74 \%$ compliance & $1(1)$ & $0(-)$ & - & 1 \\
\hline Do not know & $14(14)$ & $1.05(0.79)$ & $0.6-1.51$ & 0.19 \\
\hline No monitoring & $11(11)$ & $1.66(0.82)$ & $1.11-2.21$ & 0.57 \\
\hline No response to question & $9(9)$ & $2.65(1.37)$ & $1.6-3.71$ & 0.09 \\
\hline \multicolumn{5}{|l|}{ Barrier precautions } \\
\hline 295\% compliance & $56(57)$ & $1.3(0.97)$ & $1.04-1.56$ & Ref \\
\hline $75-94 \%$ compliance & $9(9)$ & $1.9(1.47)$ & $0.77-3.03$ & 0.13 \\
\hline $25-74 \%$ compliance & 0 & - & - & \\
\hline Do not know & $13(13)$ & $1.38(1.06)$ & $0.74-2.02$ & 0.85 \\
\hline No monitoring & $13(13)$ & $1.41(0.87)$ & $0.88-1.93$ & 0.85 \\
\hline No response to question & $8(8)$ & $2.4(1.51)$ & $1.14-3.66$ & 0.23 \\
\hline \multicolumn{5}{|c|}{ Monitoring hand hygiene practices } \\
\hline 295\% compliance & $57(58)$ & $1.28(0.96)$ & $1.03-1.54$ & Ref \\
\hline $75-94 \%$ compliance & $8(8)$ & $2.56(1.4)$ & $1.38-3.73$ & 0.035 \\
\hline $25-74 \%$ compliance & 0 & - & - & \\
\hline Do not know & $13(13)$ & $1.38(1.06)$ & $0.74-2.02$ & 0.88 \\
\hline No monitoring & $12(12)$ & $1.31(0.8)$ & $0.81-1.82$ & 0.92 \\
\hline No response to question & $9(9)$ & $2.33(1.54)$ & $1.14-3.51$ & 0.24 \\
\hline \multicolumn{5}{|l|}{ Checking line for daily necessity } \\
\hline $295 \%$ compliance & $40(40)$ & $1.27(1.03)$ & $0.94-1.6$ & Ref \\
\hline
\end{tabular}




\begin{tabular}{|c|c|c|c|c|}
\hline ICU type & $\begin{array}{c}\text { No. of } \\
\text { ICUs } \\
99(100 \%)\end{array}$ & Mean (SD) & $95 \% \mathrm{CI}$ & P value* \\
\hline 75-94\% compliance & $16(16)$ & $1.83(1.12)$ & $1.23-2.42$ & 0.05 \\
\hline $25-74 \%$ compliance & $3(3)$ & $1.72(0.58)$ & $0.27-3.16$ & 0.43 \\
\hline Do not know & $10(10)$ & $1.32(1.26)$ & $0.42-2.22$ & 0.84 \\
\hline No monitoring & $13(13)$ & $1.46(0.9)$ & $0.92-2.01$ & 0.66 \\
\hline No response to question & $17(17)$ & $1.11(1.17)$ & $0.51-1.71$ & 0.98 \\
\hline \multicolumn{5}{|l|}{ All bundle policies } \\
\hline$\geq 95 \%$ compliance with all policies & $25(25)$ & $1.3(1.35)$ & $0.74-1.86$ & Ref \\
\hline$\geq 95 \%$ compliance with 5 policies & $16(16)$ & $1.21(0.74)$ & $0.82-1.61$ & 0.87 \\
\hline$\geq 95 \%$ compliance with 4 policies & $10(10)$ & $1.2(0.71)$ & $1.69-1.71$ & 0.95 \\
\hline$\geq 95 \%$ compliance with 3 policies & $8(8)$ & $1.55(0.94)$ & $0.77-2.34$ & 0.35 \\
\hline$\geq 95 \%$ compliance with 2 policies & 0 & - & - & \\
\hline$\geq 95 \%$ compliance with 1 policy & $1(1)$ & $3.92(-)$ & - & 0.32 \\
\hline All other responses & $39(39)$ & $1.77(1.26)$ & $1.37-2.18$ & 0.23 \\
\hline
\end{tabular}

CLABSI, central line-associated bloodstream infection; ICU, intensive care unit; SD, standard deviation No hospital reported $<25 \%$ compliance with any policy; thus this compliance level not shown.

Unadjusted negative binomial regression using the sum of line device days as exposure variable to examine the association between $\geq 95 \%$ compliance with that central line bundle policy and other degrees of self-reported compliance (or other survey response) 